\title{
APPLICATION OF AUTOMATED BUILDING CONSTRUCTION SYSTEM FOR HIGH-RISE OFFICE BUILDING
}

\author{
Hiroshi Miyakawa ${ }^{\text {a }}$, Jyunichi Ochiai ${ }^{\text {b }}$, Katsuyuki Oohata ${ }^{\text {a }}$, Takashi \\ Shiokawa ${ }^{\mathrm{c}}$ \\ a Obayashi Co., Building Construction Division, Japan \\ b Obayashi Co., NEC Tamagawa Site Office, Japan \\ ${ }^{\mathrm{c}}$ Obayashi Co., Technical Research Institute, Japan
}

\begin{abstract}
High-rise steel structure buildings are generally constructed using tower cranes. But in this conventional method, quality and work schedules are easily affected by wind or rainfall, and there are many dangerous working conditions. The automated building construction system, called ABCS, is new construction method which integrates all-weather warehouse facilities, automated conveyor equipment and centralized computer control. $\mathrm{ABCS}$ is developed in order to improve productivity and the working environment compared with conventional method. In this paper, we present the report applied to a 26story steel structure high-rise building.
\end{abstract}

Key-words: automated construction, all weather, factory automation, parallel delivery, construction management system

\section{INTRODUCTION}

High-rise steel structures are usually built using tower cranes. The quality and progress of work executed by this method can be easily affected by weather conditions. The need to work at elevated levels is another problem, and the aging of construction workers and a shortage of skilled workers are aggravating problems. The Automated Building Construction System (ABCS) is a new construction system developed to solve these problems and at the same time increase productivity. ABCS employs an erection system by which to install steel members, external panels, etc., which differs from a typical conventional tower crane system, provides a working space protected from the elements by a shell. ABCS also incorporates various integrated automation and information technologies.

In 1993, the ABCS was used for the first time to build a medium-rise building (10 floors above ground). This paper reports on the application of the $\mathrm{ABCS}$ to a recently constructed steel-framed highrise building (26 floors above ground).

\section{CONSRTUCTION SITE}

The construction site is located in the premises of a company that manufactures electrical equipment. The building consists of a high-rise section (26 floors), a low-rise section and an artificial ground. A typical upper floor, which is composed of $9 \mathrm{~m} \times 9 \mathrm{~m}$ grid cells, has office spaces sandwiched by cores, plus the corresponding level of the elevator tower. The ABCS was applied to all typical floors (seventh to 26th floors) of the high-rise section (excluding the elevator tower).

Table 1. Project site data

\begin{tabular}{|c|l|}
\hline \multirow{2}{*}{ Structure } & $\begin{array}{l}\text { Underground: } \\
\text { reinforced concrete, } \\
\text { steel-frame reinforced } \\
\text { concrete } \\
\text { Aboveground: } \\
\text { steel-frame reinforced } \\
\text { concrete, } \\
\text { steel-frame } \\
\text { (3rd and higher floors) }\end{array}$ \\
\hline Number of floors & $\begin{array}{l}2 \text { basement floors, } \\
26 \text { aboveground floors, } \\
2 \text { penthouse floors }\end{array}$ \\
\hline Maximum height & approx. 110 m \\
\hline Total floor area & $79,752 \mathrm{~m}^{2}$ \\
\hline Principal intended use & Office \\
\hline Construction period & $\begin{array}{l}\text { Oct. 1997 to Jan. 2000 } \\
\text { (28 months) }\end{array}$ \\
\hline
\end{tabular}

\section{OVERVIEW OF ABCS}

\subsection{Basic system configuration}

The principal components of the ABCS are a structure that encloses the working space and a parallel delivery system.

The structure enclosing the working space, called the "SCF" (Super Construction Factory), comprises a roof and surrounding walls and is supported by columns erected on top of the steel 


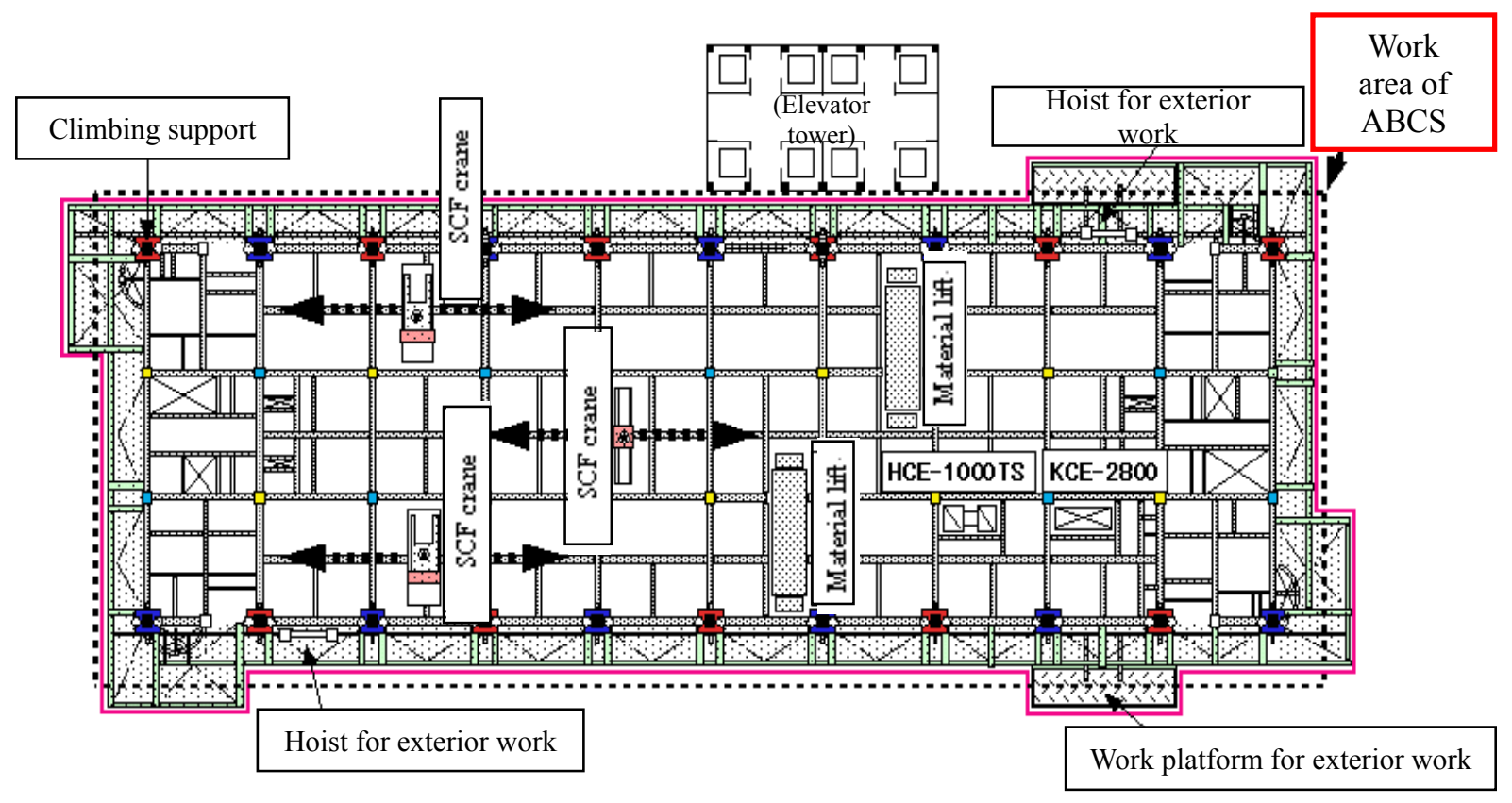

Figure 1. System plan

columns erected as part of the building frame. The parallel delivery system consists of forklifts, material lifts and overhead traveling cranes. These equipment perform horizontal transportation from the stockyard to the lifts, vertical transportation to the floor on which construction work is being carried out (construction floor), and horizontal transportation on the construction floor, respectively.

Building frame work and exterior work can be carried out in the SCF, regardless of the weather conditions. When the construction of one floor has been completed, the climbing mechanisms built in the support columns lift up the SCF to the next level. The construction of the building proceeds by repeating these steps.

\subsection{Principal mechanical equipment}

(1) $\mathrm{SCF}$

The SCF measures $33 \mathrm{~m}(\mathrm{~W}) \times 96 \mathrm{~m}(\mathrm{~L}) \times 28 \mathrm{~m}$ $(\mathrm{H})$ and weighs, including the climbing mechanisms, the SCF cranes, etc., about 2,200 tons. The roof and walls, which are covered with weatherproof sheeting, form an all-weather working space. The framework of the SCF consists largely of what is to become the top floor of the building; at the final stage of construction, SCF's main structure is lowered to become part of the building.

Since the SCF was applied to the seventh and upper floors, the SCF was assembled on the seventh floor.

\section{(2) Climbing system}

The support columns (climbing supports) erected on top of the steel columns of the building penetrate the SCF frame, and the uppermost part of each column is equipped with a climbing mechanism. The climbing mechanism was installed on all building columns in the last construction project to

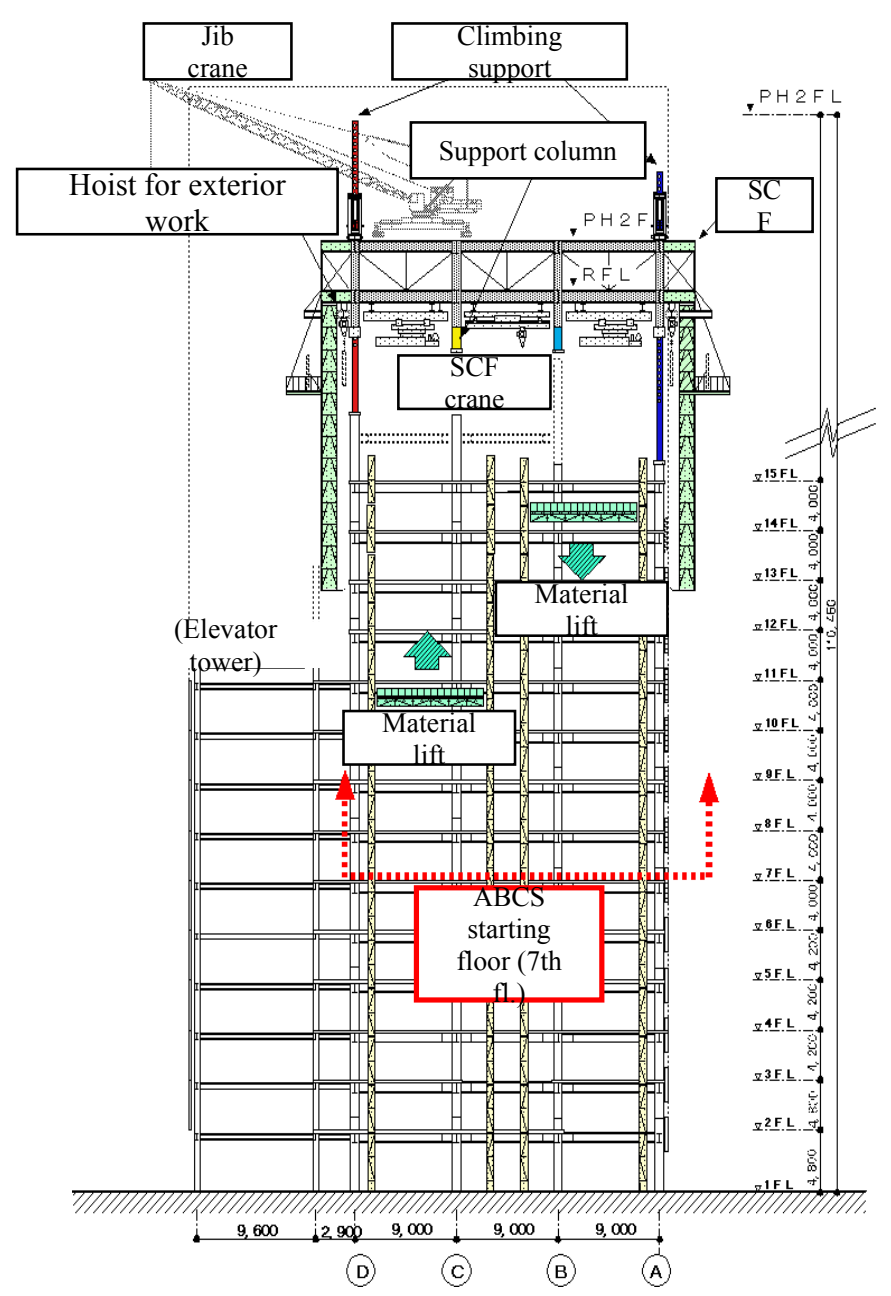

Figure 2. System cross section 
which ABCS was applied. For the project reported here, however, the climbing steps have been improved so that the number of climbing mechanisms has been reduced by half.

The climbing mechanism itself has also been modified from the rack and pinion system to the locking jack system to make the mechanism compact and thereby reduce loads acting on the SCF.

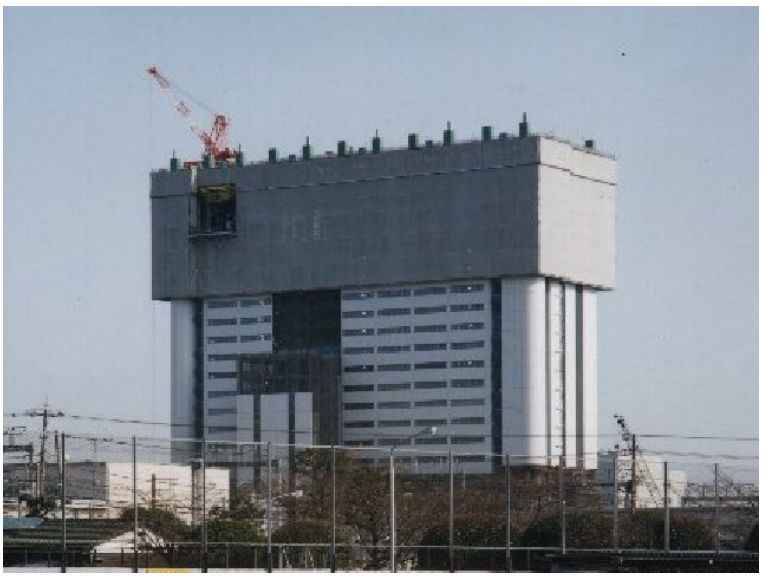

Photo 3. SCF

\section{(3) SCF cranes}

A total of three SCF cranes, one each for each span, were installed. Of these, two were 13.0 ton cranes equipped with a rotating arm. The crane in the central span had a lifting capacity of 7.5 tons, and this crane had such a mechanism that the beam slid laterally.

On the construction floor, the SCF cranes perform the horizontal transportation and installation of steel columns and beams, precast concrete floor slabs, and external paneling on the side walls of the building. The longitudinal and transverse movements of the cranes were programmed for automatic operation. Special holding devices were used to rig steel columns and beams for lifting, and unrigging was performed by remote control.

\section{(4) Material lifts}

The Material lifts were used to lift steel members, precast concrete slabs, etc., from the first floor to the construction floor. Two high-loadcapacity $(13.0$ t) high-speed lifts with a rated fullload speed of $70 \mathrm{~m} / \mathrm{min}$ were installed in the building.

\section{(5) Jib crane}

A jib crane (JCC-120N) was installed on the SCF. The jib crane was used for disassembling of the temporary portion of the SCF, lifting of external panels, and the erection of the elevator tower steel frame.

(6) Hoists for external panel installation

Precast concrete panels and aluminum panels were used for external facing. Large precast concrete panels in the girder direction were installed with dedicated hoists that were installed along the circumference of the building. The hoists were used in synchronized pairs (rated capacity $4.8 \mathrm{t} \times 2$ ).

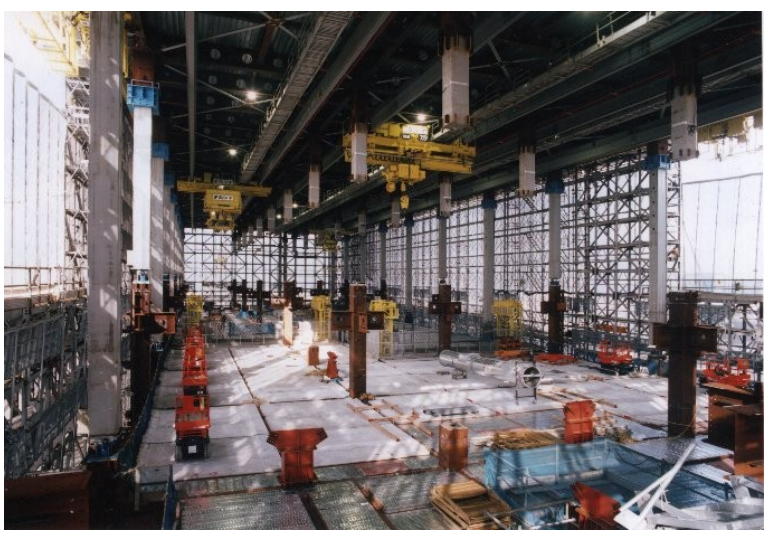

Photo 4. Inside SCF

\subsection{ABCS integrated management system}

The ABCS integrated management system consists of three subsystems: the production management system, the equipment operation management system and the machine control system.

The production management system converts design $\mathrm{CAD}$ data to construction models and performs scheduling and performance management of the delivery and installation of materials. In the performance management, information received from the equipment operation system was used to display the progress of work in three dimensions on a computer screen.

The equipment operation management system is a system that supports the automatic operation of the SCF cranes. Automatic operation data were prepared in advance on the basis of schedules produced on the production management system. Structural members were identified by scanning a bar code affixed to each member, and were automatically transported to the specified locations according to operation data. The operating status was displayed in real time so that the operating status of multiple cranes can be monitored on a personal computer in a central control room.

The machine control system is a system that controls the operations of the climbing system. Climbing operations of the SCF are controlled from an operating console installed in the central control room.

\section{APPLICATION OF ABCS AND DISCUSSION}

\subsection{Tact schedule}

A tact schedule of the construction work reported in this paper is shown in Figure 3.

In the construction schedule, the "Nth floor" is the "construction floor," on which building frame work is being carried out. The (N-1)th and (N-2)th 
floors immediately below are the "exterior work floors." The floors from $\mathrm{N}$ to $(\mathrm{N}-2)$ are enclosed by the SCF.

On the Nth floor, the cycle from the column erection (1) to the precast concrete slab installation (4) appears twice. The reason for this is that the central span, in which the 7.5-ton sliding crane was to move about, was constructed first, and then the two spans on both sides of the central span, which were to be traversed by the 13.0-ton rotating cranes, were constructed. Since the step at which loads from the SCF are supported on top of the steel columns in the central span was necessary in the SCF climbing procedure, there is the lowering $(700 \mathrm{~mm})$ of the SCF (10) in the tact schedule. These steps were planned as a six-day process, and they did take six days.

\subsection{Work efficiency}

Figure 4 shows a comparison of the unit labor requirements per floor area of the tact-based construction work. The unit labor requirements for ABCS were obtained by summing data shown in

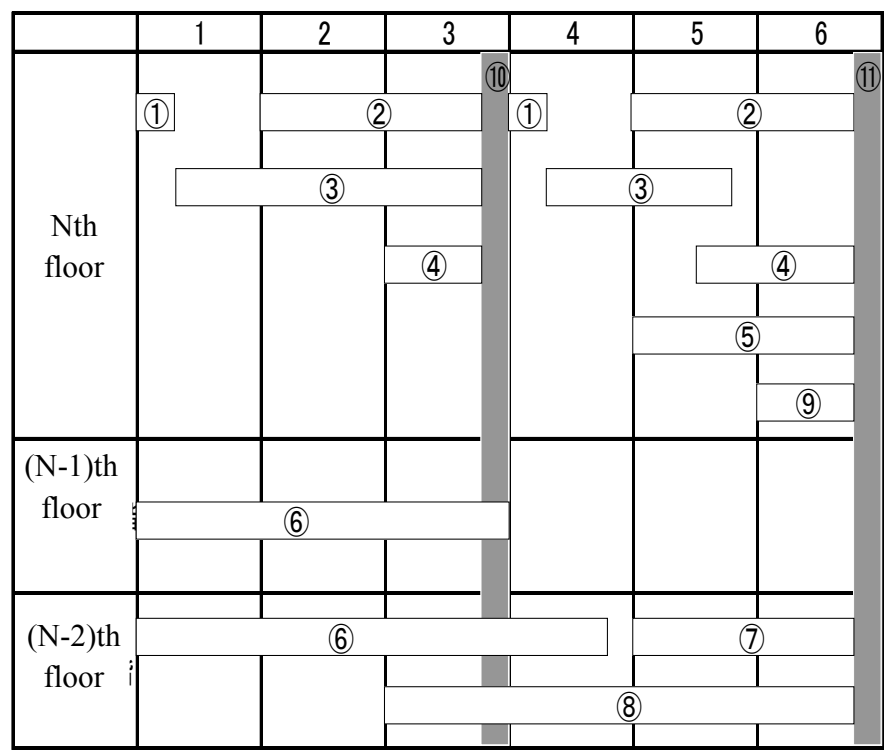

daily reports submitted during the building frame work for the 20th floor, when construction was steadily in progress, and by removing irregularities. The work categories for which unit labor requirements were calculated are building frame work (steel, precast concrete slabs, reinforcing bars, concrete), exterior work (PCCW, aluminum paneling, glazing, caulking), and associated temporary work.

The unit labor requirements of conventional construction were estimated from records of work executed by the conventional construction method. The unit labor requirements for the ABCS-based construction were 61 percent of those of conventional construction. This result can be attributed to such factors as the use of an efficient multi-mode transportation system, precast floor slabs and multiskilled workers (construction workers who are able to work in more than one area of specialty). For reference, the results of ABCS application in the previous project are also shown in Figure 4.

The production management system stores information on the time required for transporting different types of materials with the SCF cranes. Reductions in transportation time can be construed as reductions in working time resulting from the learning effect. Thus, according to the accumulated data, the time required for performing the same tasks became shorter by more than 10 percent during the period between the beginning and end of the ABCS operation, indicating a considerable learning effect.
(1) Column erection
7) Glazing
(2) Columnwelding
(8) Caulking
(3) Beam erection/final bolt tightening
(9) Material lift climbing
(4) PC slabinstallation
(5) Deck plating
(10) SCF lowering $(700 \mathrm{~mm})$
(11) SCF climbing

(6) Exterior PC/AW installation

Figure 3. Tact schedules

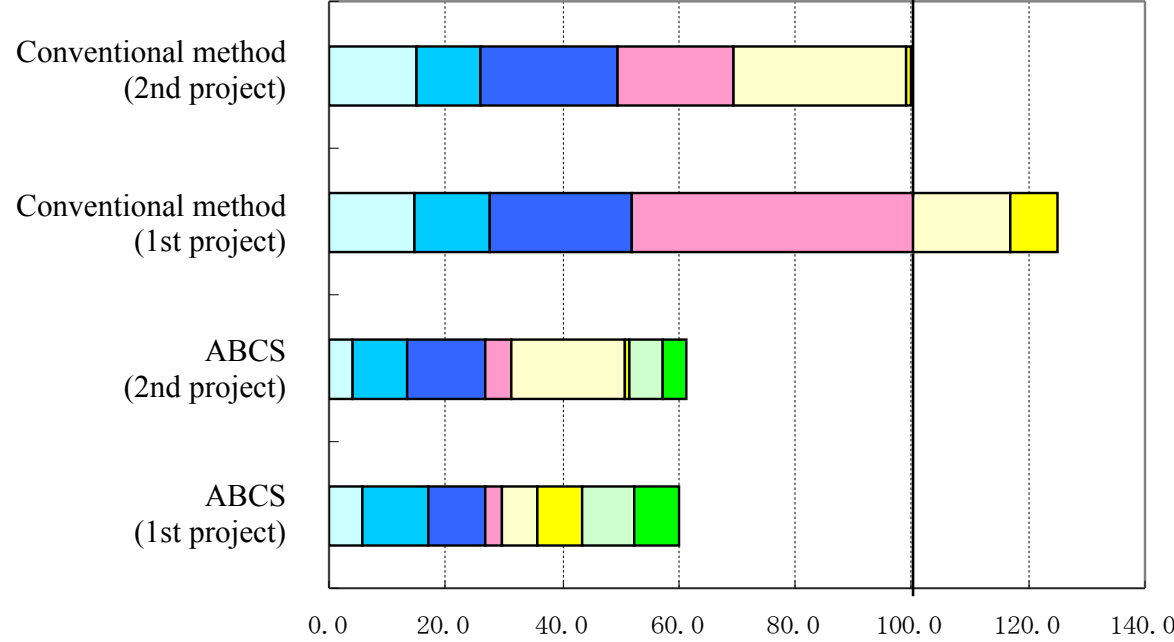

$\square$ Steel erection
$\square$ HTB, welding
$\square$ Floor work
$\square$ Safety facilities for temporary works, etc.
$\square$ Exterior work
$\square$ Marking
$\square$ Packing (per floor)
$\square$ ABCS related work

Figure 4 Comparison of unit labor requirement per floor area 


\subsection{Worker safety}

In the ABCS, floor slabs are installed by the end of each floor construction cycle. Most of the floor slabs used in the project reported in this paper are "half-precast concrete slabs." The half-precast concrete slabs used in the project are ones that have a flat top (that is, do not have any projections such as truss bars or cotters) and that can be used as a working platform as soon as they are installed. Since a firm working platform was always available, scissor-lift-type work platforms were used for final tightening of bolts and other work that needed to be performed at elevated levels. This reduced the need for scaffolding and safety equipment, which are essential for work at elevated levels in conventional construction, and dramatically reduced work on unstable scaffolding and materials for temporary works. The working environment in which workers were able to install external facing materials inside a wall that enclosed the building let them feel that they were safe.

Steel members and precast concrete slabs were installed with the SCF cranes. As the crane operators were able to operate cranes in the close vicinity of the installation sites, they were able to work in close cooperation with the installation workers. This method is superior, in terms of accuracy and safety, to the tower crane method in which instructions are sent to the tower crane operator by radio.

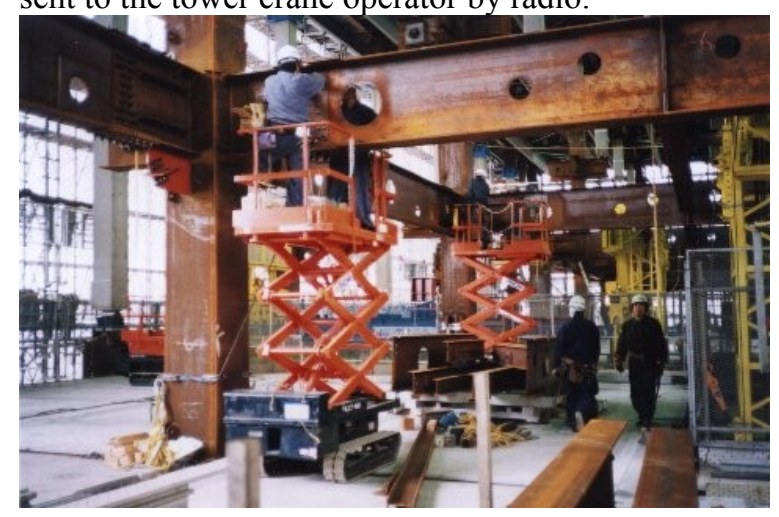

Photo 3. Final tightening of bolts using scissor lifts

\subsection{Comments from workers}

After the completion of the ABCS construction, a questionnaire survey of some of the construction workers involved was conducted.

A total of 120 workers of different work categories, including multi-skilled workers, scaffold erectors, blacksmiths, joiners, glaziers, metal workers and equipment workers, were surveyed. The respondents' ratings for questions concerning the necessity of roof, work efficiency improvement, reduction of blindingly bright light," etc., averaged 1.9 to 2.2 (smaller numbers indicating more positive attitudes) on a scale of 5.0. This indicates that the workers had favorable opinions about the installation of the roof and working environment improvements. Figure 5 presents a partial summary of the questionnaire results associated with the building frame work. The responses from finishing-related workers showed a similar tendency. These results seem to indicate that the workers had mostly positive opinions about the effect of the temporary roof provided by the SCF.

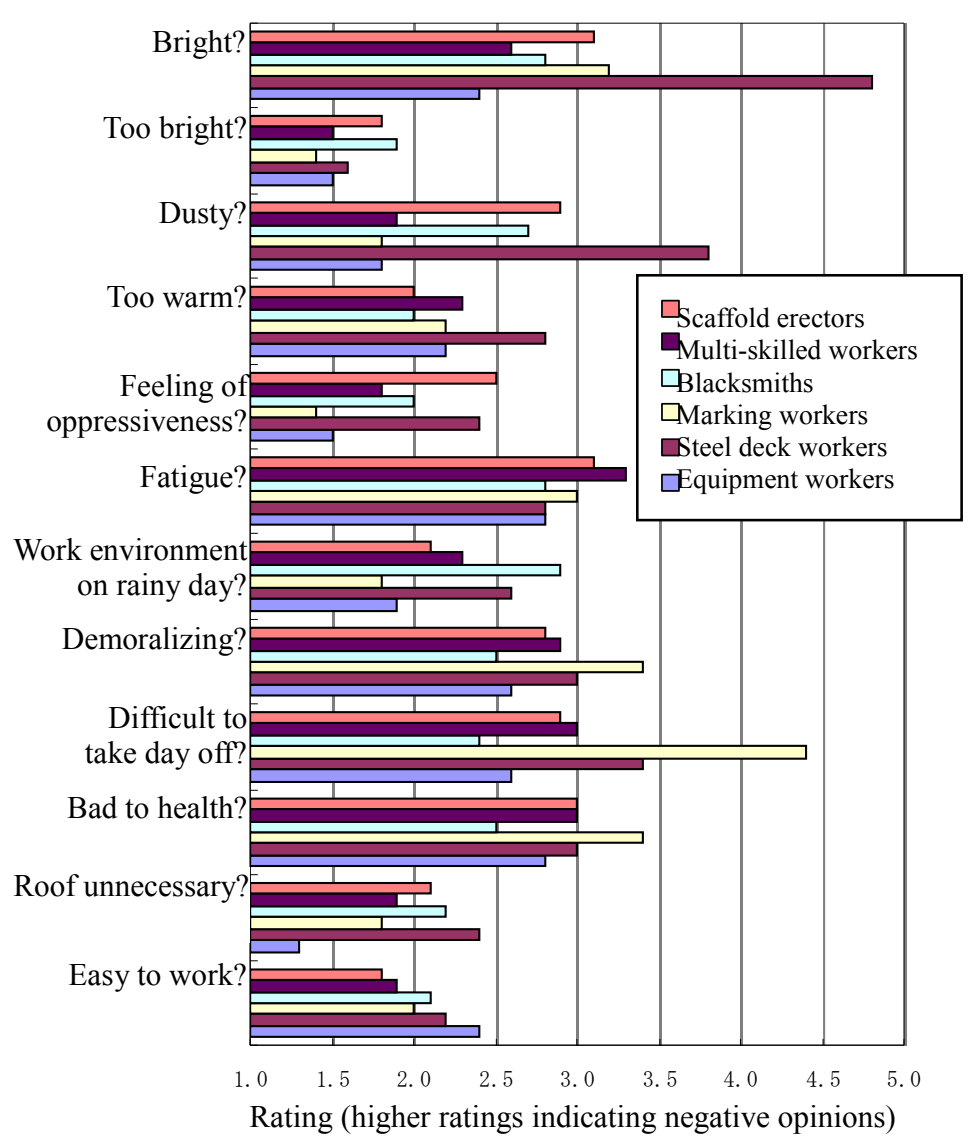

Figure 5. Working environment questionaire results (excerps)

\subsection{Automation}

In the project reported in this paper, SCF crane operations and the welding of steel columns by welding robots were automated.

SCF crane operations were not fully automated; instead, their operations consisted of automated operations up to a certain point near the specified location and manual operations for moving the crane from that location to the specified location. This method was adopted in view of the lesson learned from the last project that the method was not very cost-effective. The approach adopted this time has achieved the goal of cost reduction. Automated operations adopted for transportation and erection, however, turned out to be slower than manual operations; the advantages of the combined use of manual and automatic operations were not fully utilized.

There are a number of welding robots available on the market that are designed for use at construction sites. There are still many problems to 
be overcome, however, if they are to be operated unattended. Currently available welding robots are not yet able to replace human welders. In view of this, in the project reported here, robot welding was carried out for some columns to collect data needed to develop next-generation welding robots.

\section{TASKS AHEAD}

\subsection{Higher level of automation}

The first practical application of the ABCS was to Obayashi's own building and was more or less of a research and development nature. The second application, which is the project reported in this paper, had to be comparable in cost to the conventional construction method. Since a variety of elemental technologies for automation have been developed, attention was paid to cost-effectiveness and an attempt was made to apply automation technologies to SCF crane operations and the robot welding of columns. Existing technologies, however, have not yet reached such a level that they can replace human welders, and application in the project was only partial.

\subsection{Expanding applicability}

Because the SCF's supporting columns are to be erected on the building's steel columns and because the configuration of the SCF, SCF cranes and material lifts needs to be adapted to that of the building, buildings to which the ABCS can be applied is limited to a certain extent, at least at present.

In order to reduce the cost of the ABCS, however, it is necessary to increase the number of buildings to which one set of ABCS equipment can be applied. The ideal is to integrate design and construction from an early stage of design, but, even if it is not possible, effort should be made to improve the system so that it can be applied in a flexible way.

\subsection{Improving $S C F$}

While the roof of the SCF is constructed, construction activities directly below need to be suspended, although this is thought to be a problem common to all all-weather construction systems which use a roof structure that incorporates transportation equipment.

Once the roof has been completed, the rest of the construction work proceeds at a fast pace. The key to success implementation of the ABCS, therefore, is to shorten the time required for roof construction. Since the SCF is disassembled when the building under construction has reached its maximum height, ensuring safety during the disassembling is also important.

The structure of the SCF is now being reviewed to improve work efficiency during assembling and disassembling.

\subsection{Environmental contribution}

By constructing an environmentally friendly building by an environmentally friendly method, the owner's attitude toward the environment can be demonstrated to society. One of the reasons that the ABCS was adopted for the project reported in this paper was that the environmental friendliness of the ABCS was thought of highly by the owner.

Environmental impact is being regarded as an increasingly important index by which to evaluate construction techniques. Efforts, therefore, not only to minimize the influence on the working environment and the immediate surroundings but also to improve construction methods taking environmental friendliness into consideration will lead to overall enhancement of the quality of construction methods.

\section{CONCLUSION}

In 1989, when the ABCS concept was announced, a shortage of construction workers, particularly skilled ones, and aging of society were serious problems. In the 10 years that followed, the environment surrounding the construction industry has changed dramatically, but the problems associated with productivity and the work environment remain unsolved. Since these problems cannot be resolved in a short period of time, there is a need for consistent effort based on a long-range perspective, including the development of associated technologies.

\section{REFERENCES}

[1] H. Miyakawa, "Environmentally friendly ecoactivities and automated construction", Construction (in Japanese), Nov. 1999.

[2] T. Mori, "Applications of fully automated building construction systems", Proc. of 8 th Construction Robot Symposium (in Japanese), Jan. 1994. 